\title{
Putting the "Noun Bias" in Context: A Comparison of English and Mandarin
}

\author{
Twila Tardif, Susan A. Gelman, and Fan Xu
}

\begin{abstract}
Recently, researchers have been debating whether children exhibit a universal "noun bias" when learning a first language. The present study compares the proportions of nouns and verbs in the early vocabularies of 24 English- and 24 Mandarin-speaking toddlers ( $M$ age $=20$ months) and their mothers. Three different methods were used to measure the proportion of noun types, relative to verb types: controlled observations in three contexts (book reading, mechanical toy play, regular toy play), identical across languages; a vocabulary checklist (MacArthur Communicative Development Inventory); and mothers' reporting of their children's "first words." Across all measures, Mandarin-speaking children were found to have relatively fewer nouns and more verbs than English-speaking children. However, context itself played an important role in the proportions of nouns found in children's vocabularies, such that, regardless of the language spoken, children's vocabularies appeared dominated by nouns when they were engaged in book reading, but not when they were playing with toys. Mothers' speech to children showed the same language differences (relatively more verbs in Mandarin), although both Mandarin- and English-speaking mothers produced relatively more verbs than their children. In sum, whether or not language-learning toddlers demonstrate a "noun bias" depends on a variety of factors, including the methods by which their vocabularies are sampled and the contexts in which observations occur.
\end{abstract}

\section{INTRODUCTION}

Children's early word learning biases promise to shed light on the kinds of initial conceptual and perceptual predispositions children bring to bear in language acquisition. Variations in the expression of such biases may reveal the effects of formal language features and sociocultural variation on early vocabulary. Therefore, there is much current interest in characterizing and explaining these early biases. One important claim that has received particular attention is the suggestion that young children learn nouns more readily than verbs (Gentner, 1982). To the extent that children across languages preferentially learn nouns, the "noun bias" suggests that children have a conceptual predisposition early on to treat words as mapping onto objects. This argument would be particularly compelling if input factors (e.g., frequency) cannot explain this bias.

Recently, however, evidence has begun to accumulate to question the existence of a noun bias in children's early vocabularies. Three sets of issues have formed the center of this debate: first, the question of how to define nouns and verbs to examine the phenomenon; second, the more general issue of how to measure children's early vocabularies; and third, whether or not the noun bias is indeed a universal phenomenon shown across all languages given comparable methods of measurement. This article will address the second and third of these issues by using three different methods to measure children's early vocabularies in two of the languages that have been at the center of this debate: English and Mandarin. For the first, definitional issue, we defer to discussions in the literature (Bloom, Tinker, \& Margulis, 1993; Gentner \& Boroditsky, in press; Nelson, Hampson, \& Kessler Shaw, 1993; Tardif, 1996; Tardif, Shatz, \& Naigles, 1997) and use the categories "common noun" and "main verb" as our primary vehicles for examining the issue of a "noun bias." In addition, this article includes an examination of the role of context in sampling children's early vocabularies.

Note that this has not been a universally agreedupon convention in the literature and how one defines the category "noun" has an impact on the extent of the noun bias that is observed. Gentner's claims (Gentner, 1982; Gentner \& Boroditsky, in press) rest on the inclusion of both common and proper nouns. However, work by Tardif (1996) shows that in her Mandarin observational data, there was no noun bias in the productive vocabularies of the children, regardless of how the categories "noun" and "verb" were defined. Given that our claims rest on cross-linguistic differences and similarities, in the present article we use "common nouns" and "main verbs" and are consistent across languages and across measures.

\section{Measuring Early Vocabularies: Observational Measures versus Parental Reports}

As mentioned above, two of the primary challenges to the existence of a "noun bias" involve: (1)

(C) 1999 by the Society for Research in Child Development, Inc. All rights reserved. 0009-3920/99/7003-0007 
how to measure children's vocabularies, and (2) the universality, given comparable measurement methods, of a noun-predominant pattern across different languages. To some extent, these issues have been confounded in previous research. On the one hand, studies of Korean- (Choi \& Gopnik, 1995) and Mandarin-speaking children (Cheng, 1994; Tardif, 1996) did not find evidence for a noun bias in productive speech samples. In Tardif's study, for example, 9 of the 10 22-month-old Mandarin-speaking children produced more verb types than noun types (one child produced no nouns or verbs), and this tendency to produce more verbs than nouns was unrelated to overall vocabulary size. On the other hand, another study of Korean-speaking children (Au, Dapretto, \& Song, 1994) found a noun bias on a vocabulary checklist that the authors constructed. These authors and others (e.g., Caselli et al., 1995) argue that spontaneous speech samples are not an appropriate measure of children's vocabularies because they oversample children's use of highly frequent vocabulary items. Moreover, they suggest that verbs are particularly oversampled because of their low type-token frequencies, as reported previously in adult speech (French, Carter, \& Koenig, 1930; but see Tardif, 1996 for contradictory data in children's speech).

However, it is still not clear which measureproductive speech or parental checklist-should be considered more accurate. On the one hand, checklists might be more representative because they sample across all possible contexts and across a longer time period. Thus, they have the potential to tap into the lexicon as a whole, rather than just a select sampling. On the other hand, natural speech may be more representative, because it is more objective and not limited by maternal memory (which itself may be differentially accurate for different parts of speech). Unfortunately, none of the studies contributing to the cross-linguistic debate on the noun bias have used both checklist and observational measures on the same sample of children. For example, Au et al. (1994) used only checklists in Korean. Choi and Gopnik (1995) used (1) an Early Language Questionnaire, which required mothers to recall words that their children used in various pragmatic situations as well as naturalistic observations in Korean, and (2) a cross-linguistic comparison of Korean- and Englishspeaking children's productive speech in the same play contexts. Tardif (1996) used only observational measures, and Pine (1992) used maternal diaries and observations in English. Therefore, the issue of whether or not the noun bias exists across languages is a very difficult controversy to resolve with the currently available data.
There are two studies, however, that address the measurement issue more directly (Pine, 1992; Pine, Lieven, \& Rowland, 1996). In Pine et al.'s (1996) study, children's 50- and 100-word vocabularies were compared across three different types of measures. Specifically, Pine and colleagues collected diary and checklist data from the children's mothers as well as observational data at the point the children were reported to have reached their 50- and 100-word thresholds. They found that there were indeed differences in the proportions of common nouns in children's vocabularies across the three types of measures, even though the measures were highly correlated with each other. Specifically, the MacArthur Communicative Development Inventory (MCDI) showed higher proportions of nouns, whereas the observational data showed lower proportions of nouns, when compared to a combined measure of the children's vocabulary items that pooled across all three measures. Overall, the proportion of nouns in the observational data were closest to the proportion of nouns found in the children's total vocabularies, as obtained by pooling across the three measures. However, Pine and colleagues did not specifically examine the proportions of verbs, relative to nouns. Thus, because verbs were combined with all other nonnoun parts of speech, we do not know from these data whether verbs are overor under-represented in naturalistic speech samples. Moreover, although Pine (1992) reports that mothers are biased toward overreporting nouns in diaries of their children's vocabulary words, the consistency of individual words appearing across measures was not reported in the Pine et al. (1996) study. Thus, we still do not know how closely maternal checklist data coincide with the particular words recorded in a given observational period.

In the present study we examined the proportions of nouns and verbs in children's early vocabularies cross-linguistically by using multiple measures to compare overall patterns of vocabulary growth in different languages. In addition, we examined the correspondence across measures for both types of words by comparing the words that mothers reported their children could (and could not) say with the words that their children produced in an observational session conducted immediately prior to the mothers' filling out of the vocabulary checklist.

\section{The Role of Context}

Another methodological issue having to do with the use of both checklists and observations is the role of context. Activity context (i.e., the activities that are engaged in while a conversation takes place) is rarely 
controlled in naturalistic observations. Moreover, mothers may pay more attention to their children's language use in certain contexts than others, even though they have observed their children under a wide variety of contexts. Thus, it is possible that maternal reports may be biased toward particular contexts and not others, although this has not been systematically examined.

A number of studies have found evidence for large variations in maternal speech as a function of contextual factors, including the number, type, and presence of other speakers and hearers (Heberle, Kaufman, Grego, Hirsh-Pasek, Golinkoff, 1995), as well as the ongoing activity context (Goldfield, 1993; HoffGinsberg, 1991; Leaper \& Gleason, 1996; Lucariello \& Nelson, 1986; O'Brien \& Nagle, 1987). Given these findings of contextual differences in adult speech, one might wonder whether there are corresponding differences in children's speech and whether such variations in contexts might be partially responsible for cross-linguistic differences in children's vocabulary composition.

Context effects have been found for some aspects of children's speech, such as differences in complexity and style when interacting with different people (Dunn, Slomkowski, Donelan, \& Herrera, 1995; Killen \& Naigles, 1995) and differences in speech acts and taxonomic level due to play activity (Leaper \& Gleason, 1996; Leaper, Leve, Strasser, \& Schwartz, 1995; Lucariello \& Nelson, 1986). Moreover, at least one study has found that communicative context affects the proportion of various parts of speech (including nouns and verbs) in nursery school children (Sugárné, 1970). However, most studies have not looked explicitly at children's patterns of vocabulary use across different activity contexts. To make things more complicated, most of the cross-linguistic studies involved in the noun bias debate (Au et al., 1994; Choi \& Gopnik, 1995; Gentner, 1982; Tardif, 1996; Tardif et al., 1997) have involved different contexts for sampling children's naturalistic speech. One study (Gopnik, Choi, \& Baumberger, 1996) did control for context across their English- and Korean-speaking samples and still found language differences, but they also did not vary context systematically. Thus, it is still not clear to what extent the cross-linguistic patterns that have been found are specifically due to language, and to what extent they are due, at least in part, to differences in the activities that occurred when children's vocabularies were sampled.

Nonetheless, a study conducted by Fu, Gelman, and Behrend (1992) suggests that activity context may indeed have an important effect on the proportions of nouns and verbs that appear in adults', and possibly also children's, spontaneous speech. In the Fu et al. study, English-speaking mothers produced more verb types than noun types in a 15-minute toy-play situation with their 14- and 20-month-old toddlers. Although English-speaking mothers often produce more verb tokens than noun tokens, this tendency to produce more verb types differed from what had been found in other studies (see Goldfield, 1993; Tardif et al., 1997). However, it is quite likely that these results were related to the use of stimuli that were specifically designed to allow mothers equal opportunities to talk about the objects' movement characteristics and properties (e.g., shape, color), as well as just their labels. Thus, given a context in which the actions and properties of toys were highlighted, Englishspeaking mothers appeared to produce a pattern of nouns and verbs that was more similar to their Mandarin-speaking counterparts than to their own pattern in different contexts.

The question for the present study is whether, under controlled activity contexts that were identical for both groups, we still find cross-linguistic differences in the use of nouns and verbs for both the mothers and the children. Namely, would we still find differences in the Mandarin- and English-speaking adults' speech if we gave them activity contexts that enabled a focus on object-labeling versus contexts that enabled a focus on actions? Or would the activity contexts themselves account sufficiently for the cross-linguistic differences in noun and verb use? More important, would we also find consistent differences in the speech of the children, or would activity context be a more salient source of differences? Finally, would we find evidence of cross-linguistic differences in the proportions of nouns and verbs in the vocabularies of English- and Mandarin-speaking children across both observational and maternal report measures?

To address these questions, we provided both English- and Mandarin-speaking mother-child dyads with three experimental activity contexts that were identical across the language groups. The three contexts were chosen to elicit different types of talk from the mothers and their children. Specifically, a picture book was chosen to elicit nouns and talk about objects, a set of mechanical toys was chosen to elicit verbs and talk about actions, and a set of "regular" toys was chosen to be more neutral in this regard and to be comparable to the type of context typically chosen for naturalistic speech samples. In addition, we created a modified version of the MCDI for mothers to report their children's current vocabulary use, and also asked mothers to report retrospectively on their children's first words. 


\section{METHOD}

\section{Participants}

Twenty-four English-speaking children (12 firstborn or only children, 12 later-born) and their mothers were recruited from the subject pool in a midwestern university town in the United States. Half of the children were male and half were female. Their mean age was 20 months, 20 days ( $S D=1$ month, 1 day). The mean level of educational attainment for their mothers and fathers was 16.8 years $(S D$ mothers $=$ $1.6, S D$ fathers $=2.3$ ), or almost 5 years of postsecondary schooling. One additional child was tested in this procedure but the data were not included because of technical problems with the audiotape.

Twenty-four Mandarin-speaking children (all onlyborns) were recruited from hospital immunization records and word-of-mouth in the university area of Beijing, China. Half of the children were male and half were female, with a mean age of 20 months, 5 days ( $S D=1$ month, 5 days), which did not differ from the English-speaking children. The mean level of educational attainment of the Beijing mothers was 15.3 years $(S D=2.3)$ and the fathers was 15.4 years $(S D=2.6)$, or roughly $3 \frac{1 / 2}{2}$ years of postsecondary schooling. Although both the Beijing mothers' and fathers' educational levels were significantly lower than the U.S. mothers' and fathers' levels, it is important to note that both groups represent a population that is well above average in education for their respective societies (see Population Census Office, 1993; U.S. Bureau of the Census, 1994). Two additional Beijing children were tested, but because of difficulties in completing the play sessions, were eliminated from the sample.

\section{Procedure}

Both groups of participants were told that we were interested in studying mother-child interactions and how mothers play together with their toddlers with different types of toys.

The procedure for both groups was identical, with the order of play conditions counterbalanced within each group and matched across groups. The entire session consisted of three 10-minute play sessions with a break after the first or second session, in accordance with the dyads' own needs. After the three play sessions were completed, the mothers filled out three questionnaires: (1) the Child Development Questionnaire (CDQ), which was created by the authors and asked each mother about when her child had reached certain developmental milestones; (2) the MacArthur Communicative Development In- ventory (MCDI); and (3) a short questionnaire about the family's demographics.

In each of the play sessions, an experimenter brought the materials into the play room and asked the mothers to play with the objects (toys or book) together with their child "as they normally would at home." In addition, the experimenter pulled each of the toys out of a container (or flipped through the various pages of the book), demonstrating how to play with them. For all three sessions, the experimenter said only "oh! here's one!" ("wa! zher4 you3 yi2-ge"), "here's another one!" ("zher4 hai2 you3 yi2-ge"), or "here's some more" ("zher4 hai2 you3 yi4-xie1") as she pulled out the various objects or turned the pages of the book. We restricted the experimenter's comments so as not to bias the mothers or the children with any particular noun or verb labels for the objects or how they worked.

\section{Transcribing and Coding of Naturalistic Speech}

All three play sessions were recorded and transcribed into CHAT format (MacWhinney, 1991) by native speakers of each language. In addition, the child speech was coded as being either a repetition (exact repetition of the mother's words within one conversational turn), quoted speech (from poems, songs, or nursery rhymes), responses to test questions (questions to which the mother already knows the answer, e.g., "What's that?," "What do you do with a comb?"), or fully productive speech. Only fully productive speech and responses to test questions will be presented in this article.

Finally, the common nouns and main verbs of both the mothers and the children were coded. In addition, we also coded the children's productions of adjectives, adverbs, auxiliary verbs, grammatical particles, interjections, locatives, pronouns, quantifiers, question words, resultative verb complements (Mandarin only), and social interactive words.

\section{Materials}

\section{Toys and Book}

The play materials for both groups were identical and were chosen explicitly to be as culturally appropriate for both groups as possible. As noted earlier, a picture book was designed to provide a nouneliciting context, mechanical toys were selected to provide a verb-eliciting context, and regular toys were selected to provide a neutral (noun- and verbeliciting) context.

The picture book was created specially for this study using pictures from books that were readily 
available in either the U.S. or China. Pictures of common objects from both Chinese and American books were selected for their simplicity and familiarity in both groups, with the primary constraint that none of the pictures could contain any written letters, words, or characters. These pictures were then scanned into the computer and modified so that they would fit on pages of equal size, and were laminated and collated to form a book. Forty-three pictures were chosen to form the pages of this book (see Appendix A for a complete list).

The mechanical toys were selected to elicit talk about a varied set of movements, both ones that the toys themselves produce (e.g., hopping) and ones that people interacting with the toys produce (e.g., winding). The objects included: two plastic frogs, one that was a wind-up toy that walked sideways and moved its "arms" up and down in a "dancing" manner, and the other that was battery-operated and bounced and shook when a switch was pulled; two dinosaurs, one that rolled forward when its head was depressed, and the other that walked forward, raised its head, and roared when a switch under its belly was slid across to the "on" position; two telephones, one that resembled a cordless or mobile phone with an antenna that could be pulled and buttons that could be pushed, and one that had wheels and a rotary dial with eyes that moved up and down when it was pulled along by an attached string; and two radiolike toys, one that had a toy cassette tape that emitted a squeak when it was pushed in and control buttons on top that made clicking noises when slid from one end to the other, and the other that had a spinning dial and a push-down antenna that resulted in the playing of some music.

The regular toys were a set of multicolored wooden blocks of different shapes, two small stuffed animals (a rabbit and a duck), a toy car, and a toy motorcycle with a kickstand and removable rider.

\section{MacArthur Communicative Development Inventory (MCDI)}

A vocabulary checklist based on the MCDI, Words and Sentences (Bates, Bretherton, \& Snyder, 1988; Dale, Bates, Reznick, \& Morisset, 1989) was used for both the English and the Mandarin-speaking samples. We created a Mandarin version of the MCDI and modified the English version of the MCDI to include object labels and action words that might be produced by either the parent or the child during the experimental play sessions. In addition, we added a substantial number of verbs to balance the number of nouns and verbs on the list in the two versions.
This was important because many commonly used words in Mandarin child speech are verbs, and many of the particular verbs that are used frequently by Mandarin-speaking toddlers-for example, shout/ call (jiao4); fly (fei1) - do not appear on the original version of the MCDI.

Translations of the MCDI from English to Mandarin involved examinations of an existing database of Mandarin-speaking children's commonly produced words from 20-26 months (see the Beijing transcripts in the Mandarin corpus on the CHILDES databaseMacWhinney \& Snow, 1990; Tardif, 1993), as well as consultations with a group of parents who had young children and who worked at the Chinese Academy of Sciences, Institute of Psychology in Beijing. Occasional substitutions were made, particularly for food items (e.g., cha2, "tea," instead of coffee; zhou1, "congee," instead of sandwich), kinship terms (which are more specific in Mandarin), action words (there were many Mandarin verbs that could not be translated adequately into a single English verb, e.g., kang2, "to carry something" [slung over one's shoulder], dai4, "to wear" [a hat] versus chuan1, "to wear" [clothes]), and the more language-specific functional word categories toward the end of the Inventory, although the total number of words used in each category were made to be as equivalent as possible. A complete list of modifications to the MCDI in each language, listed by category, can be found in Appendix B. The complete Mandarin checklist, which is more appropriate for Beijing dialect than other varieties of Mandarin, can be obtained from the authors.

\section{Child Development Questionnaire}

In addition to the MCDI, mothers were asked to fill out a short questionnaire about when their child had achieved various developmental milestones. Some of these milestones were relevant to the children's current experiences, whereas others had been achieved several months before the mothers filled out the questionnaire and thus involved retrospective reports of when their children had achieved such milestones. Because of limitations on the accuracy of retrospective reports, we intend these data to be used as supplementary evidence only. Importantly, however, there is no reason to expect the accuracy to differ across languages for these retrospective reports.

There were three questions about children's first words that were of interest for the present study. These included: "When did your child first begin to say [his/her] first words so parents can understand?" ("ni3de hai2zi shen2me shi2hou4 kai1shi3 hui4 shuo1 ji3ge ci2-fu4mu3 neng2 ting1 dong3?"); "When did 
your child first use words to label objects?" ("ni3de hai2zi shen 2 me shi2hou4 kai1shi3 yong4 yu3yan2 lai2 shuo1 chu1 dong1xi de ming2zi?"); and "When did your child first use words to label actions?" ("ni3de hai2zi shen2me shi2hou4 kai1shi3 yong4 yu3yan2 lai2 miao2shu4 dong4zuo4?") After the mothers filled in their answers, they also were asked for examples of these first words. The experimenters tried to obtain three "first words" from each mother, although the number of words reported varied across participants.

\section{RESULTS}

Results are reported first for the productive vocabulary measures for the mothers and the children in both groups, and then these are compared and contrasted with the vocabulary checklist and open-ended questions about the children's first words in each of the languages.

\section{Productive Vocabulary Measures}

Repeated measures multivariate analyses of variance (MANOVAs) were used to analyze the production data for both the children and the adults across experimental settings. The two dependent variables in the model were noun types and verb types, with context as a repeated measures independent variable and language as a between-subjects variable. We report only the type (and not token) analyses here, to be concise, because the primary debate has focused on a predominance of noun types and not tokens in children's early vocabularies (see Gentner, 1982).

\section{Adult Productive Vocabulary Measures}

Overall, there were no main effects due to language or word type (noun versus verb) on the adults' productive vocabulary measures for the laboratory play sessions. (The total, or "overall," types of measures discussed for the adults' and children's productive vocabularies are not simply an addition of the number of types in each of the three activity contexts. Instead, these were calculated separately to make sure that overlapping words [i.e., words that were produced in more than one context] were counted only once.) However, as can be seen from Table 1, there was a significant interaction such that Mandarinspeaking mothers produced more verb types than noun types and English-speaking mothers produced more noun types than verb types when talking with their toddlers in the laboratory, $F(1,46)=$ 83.73, $p<.001$.

Furthermore, as can be seen from Figures 1 and 2,
Table 1 Adults' Overall Mean Noun and Verb Types and Ratios

\begin{tabular}{lccc}
\hline & & & Nouns \\
\cline { 3 - 3 } & Nouns & Verbs & Nouns + Verbs \\
\hline $\begin{array}{l}\text { English } \\
\text { Mean }\end{array}$ & 80.1 & 61.4 & .56 \\
$\quad$ SD & 19.8 & 12.9 & .04 \\
$\begin{array}{l}\text { Mandarin } \\
\text { Mean }\end{array}$ & 58.8 & 71.1 & .45 \\
SD & 12.6 & 10.1 & .05 \\
\hline
\end{tabular}

both the English- and the Mandarin-speaking adults showed a differential pattern of noun and verb use across the three activity contexts. For the book-reading context, both groups of mothers tended to use more noun types than verb types. For the two toy-play contexts this pattern was reversed, with both groups of mothers using more verb types than noun types, $F(2,92)=355.05, p<.001$ for the Context $\times$ Word Type interaction. However, there was a Context $x$ Word Type $\times$ Language interaction such that the two groups of mothers did not show identical patterns across all three contexts. In particular, the only comparison that yielded a significant language difference was for nouns in the book reading context. Specifically, the English-speaking mothers produced significantly more noun types than did the Mandarinspeaking mothers in this condition (English $M=56.3$, $S D=14.2$; Mandarin $M=42.0, S D=10.4$ ), Scheffé post hoc test, $p<.001$.

\section{Children's Productive Vocabulary Measures}

The children's productive vocabulary types in the three experimental activity contexts were analyzed in two ways. Our first and primary analysis involved all speech that the children produced except for direct repetitions and quoted speech. Then, we conducted a secondary analysis that excluded children's responses to adult test questions to examine what words children used in the absence of such maternal elicitations.

Primary analysis: all speech excluding direct repetitions and quoted speech. Overall, there were no statistically significant language differences in the total number of word types produced by these English- $(M=60.2$, $S D=41.4)$ and Mandarin-speaking toddlers $(M=$ $56.7, S D=32.9$ ). Both groups of children produced more noun types than verb types, on average, in these laboratory play contexts, $F(1,46)=46.88, p<.001$. However, there was a significant interaction between language and word type, $F(1,46)=4.34, p<.05$, such that there was more of a difference between nouns and verbs for the English-speaking children than 


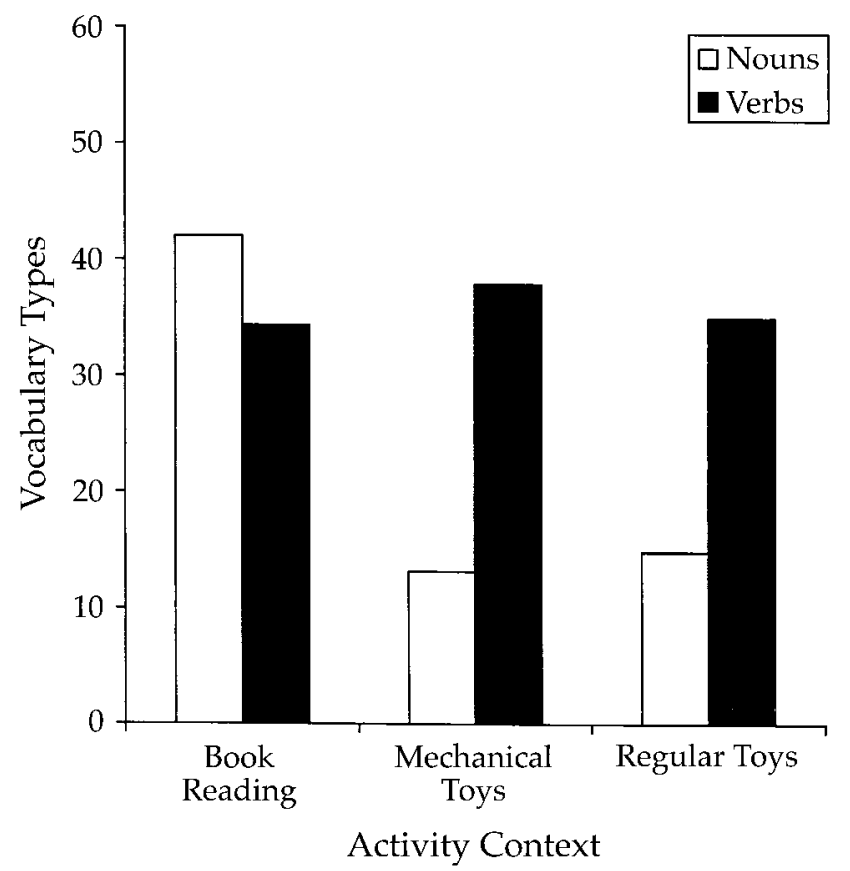

Figure 1 Mandarin-speaking mothers' mean vocabulary types.

the Mandarin-speaking children, as can be seen from Table 2.

Another way to look at this is in terms of a ratio of nouns to verbs such as the following: Nouns/(Nouns + Verbs) $\mathrm{N} /(\mathrm{N}+\mathrm{V})$. For this ratio, a score above .50 means that more nouns were produced, whereas a score below .50 means that more verbs were produced. Again, there was a significant language difference between the ratios for the English- and Mandarinspeaking children, $t(46)=2.47, p<.02$. Moreover, the English-speaking children's ratio was significantly greater than .50, whereas the Mandarin-speaking children's ratio did not differ significantly from .50. Thus, English-speaking children still showed a clear preponderance of nouns over verbs in their spontaneous vocabularies in these controlled experimental activity contexts. In contrast, Mandarin-speaking children did not share this tendency to the same extent, even though they were given identical activity contexts and their speech was coded according to identical criteria. Rather, the Mandarin-speaking children were more balanced in their production of nouns and verbs.

However, as can be seen from Table 3, there was also a strong effect of context for the children's productions of nouns and verbs, $F(2,92)=72.83, p<$ .001. Moreover, there was an interaction between word type and context for the children's productive vocabulary measures, $F(2,92)=64.05, p<.001$. Specifically, the children produced more noun types than

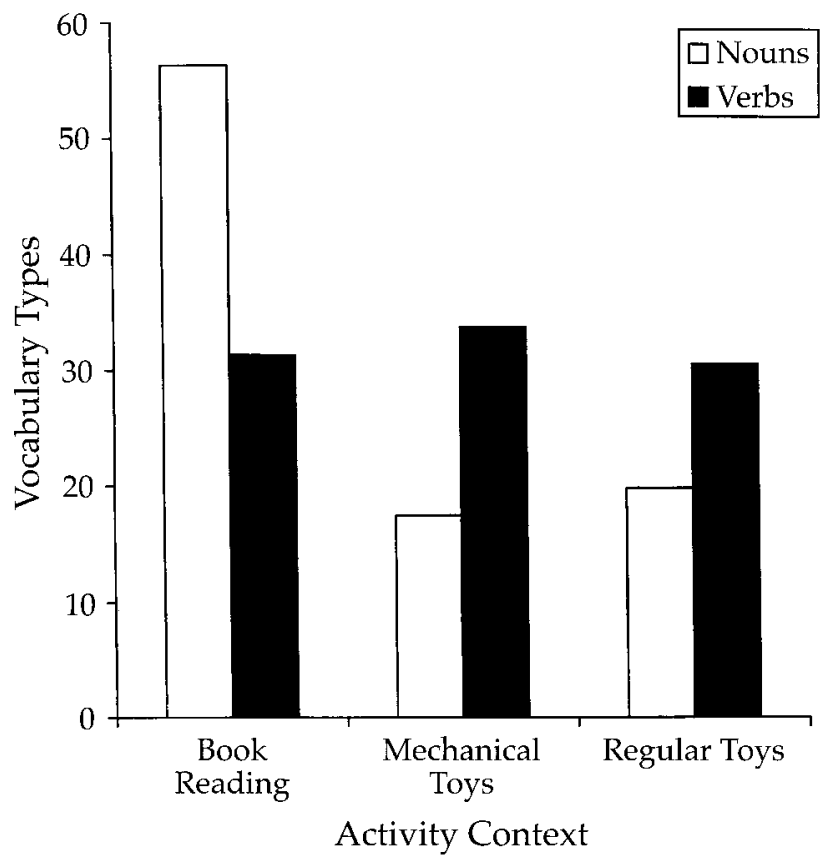

Figure 2 English-speaking mothers' mean vocabulary types.

verb types in the book reading condition, $M$ noun types $=16.3, S D=11.3 ; M$ verb types $=6.2, S D=6.1$, Scheffé $p<.001$. In the two toy play contexts, they produced more verb types than noun types $(M$ mechanical toy noun types $=2.4, S D=2.9 ; M$ mechanical toy verb types $=4.1, S D=3.6 ; M$ regular toy noun types $=4.4, S D=3.4 ; M$ regular toy verb types $=5.7$,

Table 2 Children's Overall Mean Noun and Verb Types and Ratios

\begin{tabular}{lccc}
\hline & & & Nouns \\
\cline { 3 - 3 } & Nouns & Verbs & Nouns + Verbs \\
\hline $\begin{array}{l}\text { Productive speech } \\
\text { English }\end{array}$ & & & \\
$\quad \begin{array}{l}\text { Mean } \\
\text { SD }\end{array}$ & 20.4 & 9.9 & $.68^{*}$ \\
Mandarin & 14.3 & 8.2 & .15 \\
$\quad \begin{array}{l}\text { Mean } \\
\text { SD }\end{array}$ & & & \\
$\begin{array}{l}\text { Excluding test question replies } \\
\text { English }\end{array}$ & & & .56 \\
$\quad \begin{array}{l}\text { Mean } \\
\text { SD }\end{array}$ & 16.0 & 15.0 & .19 \\
Mandarin & 11.3 & 9.4 & \\
$\quad \begin{array}{l}\text { Mean } \\
\text { SD }\end{array}$ & & 8.2 & $.63^{*}$ \\
\hline
\end{tabular}

* Denotes that the Nouns/(Nouns + Verbs) ratio is significantly different from $.50, p \mathrm{~s}<.005$. 
Table 3 Children's Mean Noun Types, Verb Types, and Total Word Types, by Language and Activity Context

\begin{tabular}{|c|c|c|c|c|c|c|}
\hline \multirow[b]{2}{*}{ Activity Context } & \multicolumn{3}{|c|}{ English } & \multicolumn{3}{|c|}{ Mandarin } \\
\hline & Nouns & Verbs & Total Types & Nouns & Verbs & Total Types \\
\hline \multicolumn{7}{|l|}{ Productive speech } \\
\hline \multicolumn{7}{|l|}{ Book reading } \\
\hline Mean & 15.5 & 4.7 & 35.4 & 17.2 & 7.8 & 37.7 \\
\hline$S D$ & 10.6 & 3.9 & 21.2 & 12.2 & 7.4 & 25.8 \\
\hline \multicolumn{7}{|l|}{ Regular toys } \\
\hline Mean & 4.9 & 4.9 & 23.3 & 4.0 & 6.5 & 22.4 \\
\hline$S D$ & 3.8 & 5.3 & 15.4 & 2.9 & 5.6 & 17.6 \\
\hline \multicolumn{7}{|l|}{ Mechanical toys } \\
\hline Mean & 2.8 & 4.0 & 17.9 & 2.1 & 4.1 & 13.5 \\
\hline$S D$ & 2.7 & 3.1 & 10.4 & 3.0 & 4.2 & 14.2 \\
\hline \multicolumn{7}{|c|}{ Excluding test question replies } \\
\hline \multicolumn{7}{|c|}{ Book reading } \\
\hline Mean & 11.0 & 4.2 & 29.2 & 5.4 & 4.7 & 18.4 \\
\hline$S D$ & 8.0 & 3.9 & 18.0 & 4.0 & 4.5 & 14.7 \\
\hline \multicolumn{7}{|l|}{ Regular toys } \\
\hline Mean & 4.4 & 4.8 & 22.3 & 2.5 & 4.8 & 15.5 \\
\hline$S D$ & 3.5 & 5.3 & 15.2 & 2.0 & 4.7 & 13.6 \\
\hline \multicolumn{7}{|l|}{ Mechanical toys } \\
\hline Mean & 2.6 & 3.8 & 17.2 & 1.7 & 3.0 & 9.6 \\
\hline$S D$ & 2.7 & 3.1 & 10.2 & 2.4 & 3.6 & 11.1 \\
\hline
\end{tabular}

$S D=5.4)$, although these differences were not statistically significant.

As can be seen from Table 3, although there was a general tendency for the Mandarin-speaking children to produce more verbs in the two toy play settings, this tendency was not statistically reliable. Moreover, the English-speaking children also showed this tendency. Thus, the expected interactions between language and word type and the three-way interaction among language, context, and word type were not found. Nonetheless, when we examined individual participants' data, there was still a clear difference in the number of children who produced more nouns than verbs versus those who produced more verbs than nouns across the two languages. Specifically, in the book reading context, none of the English-speaking children produced more verbs than nouns, whereas four of the Mandarin-speaking children still produced more verbs in this highly noun-oriented context, $\chi^{2}(1, N=46)=$ $4.38, p<.05$. Similarly, in the regular toy play context, less than half of the English-speaking children produced more verbs, whereas three-quarters of the Mandarin-speaking children produced more verbs in this "neutral" context, $\chi^{2}(1, N=43)=4.24, p<$ .05 . This can be seen more clearly in Table 4 , which presents the number of participants who showed each tendency, by condition.
Thus, there is a consistent trend for the Englishspeaking children to produce relatively more nouns and fewer verbs than the Mandarin-speaking children in these experimental activity contexts. One possibility, however, is that the English-speaking children are in fact producing more verb-like predicates than the Mandarin-speaking children, to compensate for their lack of main verbs. To address this question, we examined the total number of such predicates (excluding verbs) in both languages. Specifically, we

Table 4 Individual Children's Patterns of Vocabulary Use, by Context

\begin{tabular}{lccc}
\hline Context & $\begin{array}{c}\text { No. of } \\
\text { Children } \\
\text { More Nouns }\end{array}$ & $\begin{array}{c}\text { No. of } \\
\text { Children } \\
\text { More Verbs }\end{array}$ & $\begin{array}{c}\text { Equal } \\
\text { Number of } \\
\text { Nouns and } \\
\text { Verbs }\end{array}$ \\
\hline $\begin{array}{l}\text { Picture Book* } \\
\quad \text { English }\end{array}$ & 23 & 0 & 1 \\
$\quad$ Mandarin & 19 & 4 & 1 \\
$\begin{array}{l}\text { Regular Toys* } \\
\text { English }\end{array}$ & 10 & 11 & 3 \\
$\begin{array}{l}\text { Mandarin } \\
\text { Mechanical Toys } \\
\text { English } \\
\text { Mandarin }\end{array}$ & 4 & 18 & 2 \\
\hline
\end{tabular}

* Indicates significant differences for the two languages, $p<.05$. 
examined the children's use of adjectives (including color and state terms as well as words such as "new" and "fun," hao3wanr2), auxiliary verbs (e.g., "need" and "to want to," yao4), locatives (e.g., "up" and "here," zher4), the quantifiers "more" and "another" ("still/more," hai2, and "all gone/none," mei2 in Mandarin), and resultative verb complements (" $[\mathrm{V}+]$-exitcome," -chu1-lai2, in Mandarin only), and found that there was no difference across languages either for the total number of verb-like predicate types (English $M=8.9, S D=5.8$; Mandarin $M=10.9, S D=8.2$ ) or for the number of verb-like predicates produced in each activity context. Similarly, when we performed statistical analyses on the differences between all verb-like predicates (including verbs) and nouns, the same pattern of cross-linguistic differences reported earlier (see Tables 2, 3, and 4) appeared.

Secondary analysis: productive speech excluding test question responses. When we excluded all of the children's responses to maternal test questions and repeated the analyses of common nouns and main verbs, we found an even stronger pattern of crosslinguistic differences. Specifically, as can be seen in Table 2, the Mandarin-speaking children no longer produced more nouns than verbs when only their fully productive words (i.e., those that were not elicited by maternal test questions) were analyzed, whereas the English-speaking children continued to produce more nouns than verbs. Again, this resulted in a language by word type interaction in the twoway repeated measures analysis of variance (ANOVA) for these words, $F(1,46)=25.24, p<.001$.

Moreover, when we conducted a three-way MANOVA across the three activity contexts, we found consistent context effects, $F(2,92)=44.59, p<$ .001 , as above, but also a language by word type interaction, $F(1,46)=13.15, p<.001$, and a three-way interaction of language, word type, and context, $F(2,92)=8.41, p<.001$. The most obvious difference between these data and those presented above, which included test question replies, is that the Mandarinspeaking children no longer showed a noun bias in the book reading condition, whereas the English-speaking children still showed such a bias (see Table 3).

\section{Comparisons of Adult and Child Productive Vocabularies}

As demonstrated above, there are consistent language differences in the proportions of nouns and verbs in the speech of both children and adults. What the above analyses do not tell us, however, is whether there are also differences between child and adult speakers of these two languages. To examine this, we conducted an additional three-way ANOVA (Language $\times$ Person $\times$ Word Type) on the number of nouns and verbs in these samples of productive speech. In this analysis, there was a significant main effect for both word type and person, but not language. However, there was a three-way interaction among language, person, and word type, $F(1,92)=$ $40.01, p<.001$. Both the English-speaking adults and their children produced more noun types than verb types, Scheffé's $p s<.002$, whereas the Mandarinspeaking adults produced more verb types than noun types, Scheffé's $p<.001$, and the Mandarin-speaking children did not show a significant difference between noun types and verb types. Thus, although the children clearly produced a higher proportion of nouns than the adults, the difference between English and Mandarin was also remarkably consistent: Mandarin-speaking children and adults produced relatively fewer noun types and more verb types than English-speaking children and adults.

\section{Vocabulary Inventory Results}

Overall, the Mandarin-speaking children were reported to have more words in their vocabularies $(M=$ $316.0, S D=163.0)$ than the English-speaking children $(M=159.9, S D=130.2), t(44)=3.60, p<.001 .{ }^{1}$ Because of this overall language effect, it is more appropriate to examine the relative frequency of nouns and verbs across the two languages rather than the absolute frequency. For this reason, the remaining analyses in this section use ratio measures, Nouns/(Nouns + Main Verbs), ${ }^{2}$ rather than absolute numbers.

Using the ratio measure, the English-speaking children had a higher ratio of nouns to verbs $(M=$ $.86, S D=.11)$ than the Mandarin-speaking children $(M=.71, S D=.11), t(44)=4.79, p<.001$. What this suggests is that even though both groups of participants appear to demonstrate a "noun bias," as measured by this instrument, the Mandarin-speaking

\footnotetext{
${ }^{1}$ Two of the Mandarin-speaking children's vocabulary inventory data were not used. One mother got halfway through the second page of the seven-page inventory and then indiscriminantly checked off that her child could "understand" everything but "say" nothing. The other mother simply stopped on the third page of the inventory, despite the fact that kinship terms appeared after this and her child was quite proficient in using these terms. Thus, both of these subjects' inventories were excluded from our analyses.

${ }^{2}$ All words that fell into the Animals, Vehicles, Toys, Food, Clothes, Body, Small Household Objects, Furniture, Outside Things, and Places were summed to form the total number of "common nouns" in this ratio. Only those words that fell into the "Actions" category were used for the "main verbs" portion of the ratio, although this category was larger in our modified form of the MacArthur than in the standard form (see Appendix A).
} 
children are again significantly less noun biased than the English-speaking children.

Moreover, not all Mandarin-speaking children showed a "noun bias" pattern. Instead, one child was reported to have more verbs than nouns, and three other Mandarin-speaking children were reported to have roughly equal numbers of nouns and verbs (ratios of .50 to .60). In contrast, only two Englishspeaking children (one with a ratio of .60 , the other with a ratio of .70) were found to have ratios that fell at or below the Mandarin-speaking children's mean for this measure.

Given that there were slight differences in the items on the two vocabulary inventories due to reasons of translation and cultural appropriateness (see Appendix B), we conducted a separate analysis on the 397 overlapping words in the categories that included all common nouns and main verbs as well as onomatopoeia (sound effects) and names for people, with identical results. (Other categories, for example, pronouns, descriptive words, function words, and so forth, were excluded from this analysis of overlapping items because they were not relevant to the noun-verb contrasts and because they contained much higher proportions of language-specific items.) Specifically, the English-speaking children still had fewer vocabulary items overall $(M=107.0, S D=$ 84.7) than the Mandarin-speaking children $(M=$ $190.3, S D=89.0), t(45)=3.28, p<.005$, and the ratios for $\mathrm{N} /(\mathrm{N}+\mathrm{V})$ were still higher for the Englishspeaking children $(M=.86, S D=.13)$ than the Mandarin-speaking children $(M=.70, S D=.13)$, $t(44)=3.75, p<.001$.

One problem with interpreting these results is that other researchers have found clear evidence that the proportion of common nouns in children's vocabularies decreases as their total vocabulary increases (Bates et al., 1994). Thus, it is possible that the cross-linguistic difference in overall vocabulary size, as measured by the MCDI, may be responsible for the cross-linguistic differences in the relative proportions of nouns and verbs that were produced. We examined this issue further by conducting three additional analyses on the MCDI data.

First, we examined the pattern of cross-linguistic differences for the one third of our sample in each language that scored lowest on the MCDI. Again, the English-speaking children produced relatively more nouns and fewer verbs $(M$ ratio $=.92, S D=.14)$ than the Mandarin-speaking children $(M$ ratio $=.72, S D=$ $.14), t(14)=2.97, p<.02$. Moreover, it was clear that this difference was in the verbs, and not the nouns, as the proportion of nouns, relative to the total number of words checked off on the MCDI, did not differ for the English- and Mandarin-speaking children $(M \mathrm{~s}=$ $.52 \mathrm{for}$ both), whereas the proportion of verbs differed dramatically ( $M$ English Verbs/Total $=.03, S D=.04$; $M$ Mandarin Verbs/Total $=.20, S D=.10), t(14)=$ $4.57, p<.001$.

Next, we examined the pattern of differences for the highest scoring third of our samples. Yet again, we found a consistent pattern of results with a higher $N$ / $(\mathrm{N}+\mathrm{V})$ ratio for the English-speaking children $(M=$ $.79, S D=.07)$ than for the Mandarin-speaking children $(M=.69, S D=.06), t(14)=2.95, p<.02$. Once again, the difference was in verbs and not nouns $(M$ English Verbs/Total $=.16, S D=.05 ; M$ Mandarin Verbs $/$ Total $=.24, S D=.04), t(14)=3.34, p<.005$.

Finally, because there were still differences in the total vocabulary scores for the top and bottom thirds of the English and Mandarin samples, we matched across languages to find 11 pairs of participants, each of whose total vocabulary scores differed by 20 or fewer words (English $M$ total vocabulary $=252.6$; Mandarin $M=255.1$ ). Even under this highly conservative method of matching, the English-speaking children's $\mathrm{N} /(\mathrm{N}+\mathrm{V})$ ratios were higher $(M=.82$, $S D=.10)$ than those of the Mandarin-speaking children $(M=.74, S D=.13), t(20)=1.79, p<.05$, onetailed. Thus, the differences between nouns and verbs across the two languages appear to be not only consistent across measures, but also consistent at all levels of vocabulary size.

\section{Consistency across Observational and Checklist Measures}

As can be seen from a comparison of the ratio measures in Table 2, estimates of the proportion of nouns, relative to verbs, in children's vocabularies appear higher when measured through vocabulary checklists, such as the MCDI, than through spontaneous speech, such as the experimental activity contexts used in the present study.

To examine the consistency and the relative biases of these two types of measures, we performed two sets of analyses on the data from each language. First, we computed Pearson correlations between the total number of common noun (or verb) types that the children produced in the experimental activity contexts and the common nouns (or verbs) that the mothers reported their children were "able to say" from the MCDI. This set of analyses is parallel to those conducted by Pine et al. (1996). Second, we performed a further analysis of the words themselves and looked at: (1) the words that were both produced and reported as being in the children's vocabularies (on the MCDI), and compared these to (2) words that were 
produced but not checked off on the MCDI, as well as (3) words that were checked off on the MCDI but not produced, for nouns and verbs as separate categories. These analyses were not conducted in Pine et al.'s study.

Correlations between the numbers of noun and verb types that the children produced and the numbers of nouns and verbs that their mothers reported they could say were, in general, comparable to what previous studies have found (Hampson, 1989; Pine et al., 1996). Namely, the English-speaking children $(n=24)$ had a correlation of $.78, p<.001$, and the Mandarin-speaking children $(n=22)$ had a correlation of .66, $p<.001$, between the total number of common noun types that they produced and the number of common nouns that their mothers reported they could say on the checklist. For verbs, the correlation was $.70, p<.001$ for the English-speaking children and $.47, p<.05$ for the Mandarin-speaking children. Thus, although the proportion of nouns was higher for the checklist than for the observational data, the two measures correspond reasonably closely to each other in terms of how many nouns or verbs a particular child has, relative to other children who speak the same language. These results do not tell us, however, whether one of the instruments is more or less biased than the other.

To examine the issue of bias, we compared the actual words (rather than the overall numbers of words) that were produced in the experimental activity contexts with those words that the children's mothers checked off on the MCDI. If mothers are wholly accurate reporters of their children's speech, then all of the nouns and verbs that were produced should have been checked off on the MCDI. In fact, however, there was a significant difference between the two categories of words for both English and Mandarin speakers. That is, for the English-speaking children, a higher proportion of the nouns that were produced were also checked off on the list ( $M$ nouns $=.61, S D=$ $.22 ; M$ verbs $=.34, S D=.31), p<.001$. Likewise, for the Mandarin-speaking children, the proportion of nouns that were produced and checked off was higher than the proportion of verbs that were produced and checked off ( $M$ nouns $=.69, S D=.21 ; M$ verbs $=.57, S D=.28), p<.05$. Moreover, of the words that were produced, a higher proportion of verbs than nouns were not checked off on the MCDI by the mothers for English ( $M$ nouns $=.29, S D=.25 ; M$ verbs $=$ $.63, S D=.32), p<.001$, though this was not significantly so for Mandarin ( $M$ nouns $=.23, S D=.23 ; M$ verbs $=.34, S D=.30)$. In other words, the Englishspeaking mothers were more likely to forget the verbs that their children could (and did) say than they were to forget the nouns that their children could say. This difference existed even though these words appeared on the list and had just been spoken in the experimental session that preceded the mothers' completion of the MCDI.

Yet another indication of language differences was found when we examined the words that were produced but that did not appear on the MCDI. Specifically, the English-speaking children were more likely to produce nouns that were not on the MCDI $(M=$ $.10, S D=.09)$ than they were to produce verbs that were not on the list $(M=.03, S D=.05), p<.005$. For Mandarin, there were no differences between nouns and verbs in the number that were produced but not on the MCDI (nouns $M=.08, S D=.08$; verbs $M=$ $.09, S D=.07)$. Thus, it appears that our addition of a large number of verbs to the English version of the MCDI resulted in a more exhaustive sampling of the verbs that children were likely to produce in English, as compared to nouns, and that our MCDI data may even underestimate the proportion of nouns in English-speaking children's vocabularies.

Nonetheless, in English, as in Mandarin, there were no differences between nouns and verbs in the proportion of words that were produced as a function of the total number of words that mothers reported their children could say on the MCDI (English nouns $M=.15, S D=.09$, English verbs $M=.15, S D=.11$; Mandarin nouns $M=.10, S D=.06$, Mandarin verbs $M=.13, S D=.09$ ). That is, for both nouns and verbs, the children produced roughly 10 to $15 \%$ of the total number of word types that their mothers reported they "could say" in this 30-min sample of their speech.

\section{First Words}

A repeated measures MANOVA (Language $\times$ Word Type) was used to examine cross-linguistic differences in the age at which mothers reported their children began to produce their first words, first object labels, and first action words. Overall, the Englishspeaking mothers reported that their children produced their first words ( $M=10.9, S D=2.9$ months) at a younger age than the Mandarin-speaking mothers $(M=13.1, S D=3.3$ months $), F(1,44)=6.14, p<.05$, for a main effect of language. In addition, there was a main effect of word type, $F(2,88)=32.74, p<.001$, such that mothers reported the children produced their first words and their first words for objects before they produced words for actions, $p \mathrm{~s}<.01$ for Scheffé's post hoc tests of means. The interaction between language and word type was not statistically significant, although it is worth noting that the two groups of mothers differed in when they said that 
Table 5 Number of Children Reported to Produce One or More of the Following Word Types among Their "First Words"

\begin{tabular}{ccccc}
\hline & $\begin{array}{c}\text { Proper } \\
\text { Names } \\
\text { and } \\
\text { Kinship } \\
\text { Terms }\end{array}$ & $\begin{array}{c}\text { Common } \\
\text { Nouns }\end{array}$ & $\begin{array}{c}\text { Verbs } \\
\text { or Verb } \\
\text { Phrases }\end{array}$ & $\begin{array}{c}\text { Other } \\
\text { Predicates, } \\
\text { Social, } \\
\text { Ambiguous }\end{array}$ \\
\hline $\begin{array}{c}\text { English } \\
(n=23)\end{array}$ & 18 & 12 & 1 & 5 \\
$\begin{array}{c}\text { Mandarin } \\
(n=24)\end{array}$ & 13 & 9 & 15 & 7 \\
\hline
\end{tabular}

their children's first words (see above) and first object labels appeared (English $M=12.4, S D=2.5$ months; Mandarin $M=14.6, S D=3.6$ months), Scheffé's $p$ s < .05 , but not in when their first words for actions appeared (English $M=16.0, S D=4.1$ months; Manda$\operatorname{rin} M=17.3, S D=3.9$ months).

More importantly, there was a substantial difference across languages in the types of words mothers reported as their children's "first words." As can be seen from Table 5, the main differences occurred in the number of children who produced verbs or verb phrases as among their first words. A chi-square analysis performed on the number of children who had one or more verbs (the mothers were asked to report three "first words") versus those children who had no verbs in each of the languages confirmed that Mandarin-speaking children produced significantly more "first words" that are verbs than English-speaking children, $\chi^{2}(1, N=47)=20.67, p<$ .001 . Moreover, a simple comparison between the total number of children reported to have produced any form of nominal (common or proper noun) versus nonnominals (verbs, social-interactional words, and other predicates) further confirmed these crosslinguistic differences in the patterns of children's "first words," $\chi^{2}(1, N=47)=9.67, p<.005$.

\section{DISCUSSION}

To return to our initial questions of whether we would still find evidence for language differences in adults' productive speech samples and children's early vocabulary use in English and Mandarin if we controlled for context and measurement type, our results suggest a clear "yes."

When we looked at the overall results from the production data, consistent language differences were found for the proportion of nouns, relative to verbs, in both adult and child speech. Specifically, Mandarin speakers used a relatively higher proportion of verb types in their productive speech vocabularies than did English speakers. However, consistent with the claims made by Gentner (1982) and others, children used a higher proportion of nouns than adults. On the one hand, these results could be used to support the idea of a "noun bias" that operates at a conceptual level to facilitate the learning of nouns in early stages of vocabulary acquisition. On the other hand, it is important to note that the actual appearance of a "noun bias" as a statistically reliable preponderance of nouns is not consistent across languages when measuring vocabulary from productive speech samples. In particular, the expected preponderance of noun types was found for English-speaking toddlers, but not for Mandarin-speaking toddlers, when interacting with their mothers in activity contexts that were identical across languages. This was true even when we expanded the category of verbs to include other verblike predicates. Thus, with an independent sample of Beijing toddlers and in a controlled set of contexts, we have replicated the previously reported finding that Mandarin-speaking children do not show evidence of a noun bias in productive speech samples of their vocabulary (Tardif, 1996; Tardif et al., 1997).

Context, however, turned out to be an important source of variation in vocabulary use for both mothers and toddlers. Specifically, when given a picture book to look at, English- and Mandarin-speaking mothers and their toddlers used more noun types than verb types. When given toys to play with, the mothers in each group used more verb types than noun types, whereas their children used roughly equal numbers of nouns and verbs (although the majority of Mandarin-speaking children used more verbs than nouns). Thus, whether or not children use more nouns in their productive speech depends greatly on the contexts in which their speech is sampled.

In addition, when we excluded children's responses to maternal test questions, the cross-linguistic differences became even more obvious. Specifically, the book reading context for the Mandarin-speaking children no longer resulted in a predominance of nouns. In contrast, the English-speaking children continued to produce many more nouns than verbs in this context even though those nouns were not explicitly prompted by their mothers' test questions. This suggests that the Mandarin-speaking mothers were more focused on asking test questions to elicit nouns than the English-speaking mothers, and that the Mandarin-speaking children were producing nouns more "on demand" in this context, as compared to the English-speaking children. This finding, if substantiated, may be accounted for by cultural differences in mothers' tendencies to engage their young children 
in didactic interactions, as discussed elsewhere (Erbaugh, 1992; Lau, 1996).

Results from the MCDI also showed cross-linguistic differences, with mothers of English-speaking children reporting relatively higher ratios of nouns in their children's early vocabularies than mothers of Mandarin-speaking children. Nonetheless, consistent with the results discussed by Au and others (Au et al., 1994; Caselli et al., 1995), both groups of children were reported to have a predominance of nouns in their early vocabularies, as measured by the MCDI. Whether this reflects a more accurate measure of vocabulary knowledge than the productive speech data reported above, however, is not clear from simple comparisons of the proportions of nouns, relative to verbs, that appear in children's vocabularies for each of these measures.

To examine the accuracy issue more directly, we looked at individual nouns and verbs that appeared in both measures and compared these to words that appeared in one measure but not the other. From these analyses we found that mothers' reports of their children's vocabulary knowledge on the MCDI were biased in the direction of underestimating the proportions of verbs, relative to nouns, in children's early vocabularies. In this sense, our data support Pine's (1992) earlier finding that maternal reporting in the form of diaries is more focused on nouns than on other parts of speech. The converse notion, that observational data may be more biased toward verbs (cf. Caselli et al., 1995), is not supported by our data. Instead, our data suggest that mothers are more attuned to the nouns that their children use and are not very reliable reporters of the verbs that they use, even when these verbs were produced just minutes before completing the MCDI. Moreover, the English-speaking mothers appeared to be particularly unreliable reporters of the verbs in their children's vocabularies, as evidenced by the high proportion of verbs that the children produced but the mothers failed to report on the MCDI. Why this might be the case and whether this finding will hold up under further scrutiny is a question that remains for future research. Nonetheless, it is interesting to note the close correspondence between children's proportions of nouns, relative to verbs, in the book reading condition, as shown in Table 3, and mothers' reporting of their children's vocabulary knowledge on the MCDI. A possible interpretation of this finding is that mothers not only are particularly attuned to the nouns that their children produce, but also more attentive to their children's vocabulary use when engaging in book reading or other such "language learning" activities (cf. Ratner \& Bruner, 1978).
Finally, when we examined children's first words, we again found evidence for differences in nouns and verbs across the two samples. When the mothers were asked to give examples of words their children used as "first words," only one English-speaking child was reported to have produced a verb, whereas the majority of Mandarin-speaking children were reported to have produced one or more verbs among their "first words."

Thus, even in the earliest stages of acquisition it appears that verbs constitute a large proportion of the words that Mandarin-speaking children can and do say, and in this sense they are different from the English-speaking children. However, they are also similar to the English-speaking children in that nouns are still an important category, whether one looks at "first words," vocabulary checklists, or observational data.

\section{Conclusions}

In sum, there is no question that nouns are an early and important category for language-learning toddlers, even in Mandarin. However, the conclusion that we can draw from this and other research is that whether or not children demonstrate a "noun bias" in the early stages of vocabulary acquisition depends on a variety of factors, including the methods by which their vocabularies are sampled and the contexts in which observations occur.

Context also is not an issue limited to naturalistic recordings of children's speech-the mothers in this study reported proportions of nouns that were most closely aligned with their children's speech while looking at a picture book. Although looking at picture books is certainly an important context for many children, it is not a universal activity across all cultures or even across all socioeconomic groups within a culture, nor would one want to claim that it is the only context in which vocabulary learning occurs, even for middle-class English-speaking children. Thus, context appears to play a large role in understanding the composition of children's early vocabularies, regardless of the ways we choose to measure these vocabularies.

Finally, even if nouns receive a conceptual advantage over verbs and other parts of speech, which is an issue our data do not address, there are consistent cross-linguistic differences across all measures in the extent to which children manifest this advantage. This suggests that input factors consistent with these cross-linguistic differences (see Tardif et al., 1997) cannot be ruled out.

The question that remains for further research is how children combine these factors to learn their 
early words. For instance, are some activity contexts more effective for vocabulary learning than others, or do children use different processes to learn words in different contexts (and/or in different languages)? We believe that the answers to these and other fundamental questions about early vocabulary acquisition can be more fruitfully pursued once the roles of context and cross-linguistic variation in the "noun bias" are taken into account.

\section{ACKNOWLEDGMENTS}

We thank the parents and children who participated in the study, and Wendy Aaronson, Ryan Kettler, Lixing Leng, Shanping Qiu, Rachel Salinas, Binhua Song, Zongping Xiang, Hongli Zhang, and Jianxin Zhang for their able assistance. This research was made possible with a travel grant from the University of Michigan, Department of Psychology and Chinese Academy of Sciences, Institute of Psychology Collaborative Research Program, and the kind coordination of Professors Qicheng Jing and Harold Stevenson. Support for this project came from a Canadian Social Sciences and Humanities Research Council Postdoctoral Fellowship to the first author while she was a Fellow in the Michigan Society of Fellows and a Direct Grant for Research from the Social Sciences and Education Panel, Chinese University of Hong Kong, as well as from NSF Grant 91-00034 and a J. S. Guggenheim Fellowship to the second author.

\section{ADDRESSES AND AFFILIATIONS}

Corresponding author: Twila Tardif, Department of Psychology, Chinese University of Hong Kong, Shatin, New Territories, Hong Kong; e-mail: ttardif@ psy.cuhk.edu.hk. Susan A. Gelman is at the University of Michigan, Ann Arbor; and Fan Xu is at the Chinese Academy of Science, Beijing.

\section{REFERENCES}

Au, T. K., Dapretto, M., \& Song, Y. K. (1994). Input vs. constraints: Early word acquisition in Korean and English. Journal of Memory and Language, 33, 567-582.

Bates, E., Bretherton, I., \& Snyder, L. (1988). From first words to grammar: Individual differences and dissociable mechanisms. New York: Cambridge University Press.

Bates, E., Marchman, V., Thal, D., Fenson, L., Dale, P., Reznick, J. S., Reilly, J., \& Hartung, J. (1994). Developmental and stylistic variation in the composition of early vocabulary. Journal of Child Language, 21, 85-123.

Bloom, L., Tinker, E., \& Margulis, C. (1993). The words children learn: Evidence against a noun bias in early vocabularies. Cognitive Development, 8, 431-450.
Caselli, M. C., Bates, E., Casadio, P., Fenson, J., Fenson, L., Sanderl, L., \& Weir, J. (1995). A cross-linguistic study of early lexical development. Cognitive Development, 10(2), 159-200.

Cheng, S.-W. (1994). Beginning words of three children acquiring Mandarin Chinese. Manuscript in preparation, National Chung Cheng University, Taiwan, as cited in Caselli, et al., 1995.

Choi, S., \& Gopnik, A. (1995). Early acquisition of verbs in Korean: A cross-linguistic study. Journal of Child Language, 22(3), 497-529.

Dale, P. S., Bates, E., Reznick, S., \& Morisset, C. (1989). The validity of a parent report instrument of child language at 20 months. Journal of Child Language, 16, 239-250.

Dunn, J., Slomkowski, C., Donelan, N., \& Herrera, C. (1995). Conflict, understanding, and relationships: Developments and differences in the preschool years. Early Education and Development, 6(4), 303-316.

Erbaugh, M. S. (1992). The acquisition of Mandarin. In D. I. Slobin (Ed.), The crosslinguistic study of language acquisition (Vol. 3, pp. 373-455). Hillsdale, NJ: Erlbaum.

French, N. R., Carter, C. W., \& Koenig, W. (1930). The words and sounds of telephone conversations. Bell Systems Technical Journal, 9, 290-324.

Fu, P., Gelman, S. A., \& Behrend, D. A. (1992, April). Preponderance of nouns in children's early vocabulary: An examination of the role of linguistic and non-linguistic input. Paper presented at Conference on Human Development, Atlanta, GA.

Gentner, D. (1982). Why nouns are learned before verbs: Linguistic relativity versus natural partitioning. In S.A. Kuczaj (Ed.), Language development: Vol. 2. Language, thought and culture (pp. 301-334). Hillsdale, NJ: Erlbaum.

Gentner, D., \& Boroditsky, L. (in press). Individuation, relativity, and early word learning. In M. Bowerman \& S. Levinson (Eds.), Language acquisition and conceptual development. England: Cambridge University Press.

Goldfield, B. A. (1993). Noun bias in maternal speech to one-year-olds. Journal of Child Language, 20, 85-99.

Gopnik, A., Choi, S., \& Baumberger, T. (1996). Cross-linguistic differences in early semantic and cognitive development. Cognitive Development, 11(2), 197-227.

Hampson, J. (1989). Elements of style: Maternal and child contributions to the referential and expressive styles of language acquisition. Unpublished doctoral dissertation, City University of New York.

Heberle, J. F., Kaufman, D., Grego, J., Hirsh-Pasek, K. \& Golinkoff, R. M. (1995, March). Context effects on linguistic input and development of children's language. Poster presented at the Biennial Meeting of the Society for Research in Child Development, Indianapolis.

Hoff-Ginsberg, E. (1991). Mother-child conversation in different social classes and communicative settings. Child Development, 62, 782-796.

Killen, M., \& Naigles, L. R. (1995). Preschool children pay attention to their addressees: Effects of gender composition on peer disputes. Discourse Processes, 19, 329-346.

Lau, S. (Ed.). (1996). Growing up the Chinese way: Chinese child and adolescent development. Shatin, Hong Kong: The Chinese University Press. 
Leaper, C., \& Gleason, J. B. (1996). The relationship of play activity and gender to parent and child sex-typed communication. International Journal of Behavioral Development, 19, 689-703.

Leaper, C., Leve, L., Strasser, T., \& Schwartz, R. (1995). Mother-child communication sequences: Play activity, child gender, and marital status effects. Merrill-Palmer Quarterly, 41, 307-327.

Lucariello, J., \& Nelson, K. (1986). Context effects on lexical specificity in maternal and child discourse. Journal of Child Language, 13, 507-522.

MacWhinney, B. (1991). The CHILDES project: Tools for analyzing talk. Hillsdale, NJ: Erlbaum.

MacWhinney, B., \& Snow, C. (1990). The Child Language Data Exchange System: An update. Journal of Child Language, 17, 457-472.

Nelson, K., Hampson, J., \& Kessler Shaw, L. (1993). Nouns in early lexicons: Evidence, explanations and implications, Journal of Child Language, 20(1), 61-84.

O’Brien, M., \& Nagle, K. J. (1987). Parents' speech to toddlers: The effect of play context. Journal of Child Language, 14, 269-279.

Pine, J. M. (1992). How referential are "referential" children? Relationships between maternal-report and observational measures of vocabulary composition and usage. Journal of Child Language, 19, 75-86.

Pine, J. M., Lieven, E. V. M., \& Rowland, C. (1996). Observational and checklist measures of vocabulary composition: What do they mean? Journal of Child Language, 23, 573-589.

Population Census Office, State Council and Department of Population Statistics (1993). Tabulation on the 1990 population census of the People's Republic of China. Beijing: State Statistical Bureau of the People's Republic of China.

Ratner, N., \& Bruner, J. (1978). Games, social exchange, and the acquisition of language. Journal of Child Language, 5 , 391-402.

Sugárné, K. J. (1970). A szokincs és a szófajok gyakoriságának alakulása 3-6 éves gyermekek beszédének feladatmegoldás, illetöleg kommunikáció során [Changes in the frequency of lexical items and categories in the speech of children between 3 and 6 during the course of communication and following directions]. Altalános Nyelvészeti Tanulmányok, 7, 149-159.

Tardif, T. (1993). Adult-to-child speech and language acquisition in Mandarin Chinese. Unpublished doctoral dissertation, Yale University, New Haven, CT.

Tardif, T. (1996). Nouns are not always learned before verbs: Evidence from Mandarin speakers' early vocabularies. Developmental Psychology, 32(3), 492-504.

Tardif, T., Shatz, M., \& Naigles, L. (1997). Caregiver speech and children's use of nouns versus verbs: A comparison of English, Italian, and Mandarin. Journal of Child Language, 24, 535-565.

U.S. Bureau of the Census (1994). Statistical abstract of the United States, 114th Edition. Washington, DC: U.S. Bureau of the Census.

\section{APPENDIX A}

\section{LIST OF PICTURES IN PICTURE BOOK}

lion; soccer ball; saucepan; butterfly; dinosaur; girl with cat; turtle; boy listening to his wristwatch; boy standing astride; bulldozer; duck; shoes; carrots; bear; telephone, saw, clown hat; violin and bow; mouse; dandelions; comb; boy shoveling in sandbox; car; umbrella; apple with slice removed; kite; frog; hat and mitten; bird; hammer; dog; coat; tree; teapot; doll; chair; mushrooms in grass; airplane; gorilla; motorcycle; pencil; cow; sailboat; beetles; tractor

\section{APPENDIX B}

\section{LIST OF CHANGES, BY CATEGORY AND LANGUAGE, TO THE MACARTHUR COMMUNICATIVE DEVELOPMENT INVENTORY}

\begin{tabular}{|c|c|c|c|c|}
\hline Category & English Modifications & $\begin{array}{c}n \text { of } \\
\text { Words }\end{array}$ & Mandarin Modifications & $\begin{array}{c}n \text { of } \\
\text { Words }\end{array}$ \\
\hline Sound effects & No changes & 12 & $\begin{array}{l}\text { Substitutions: choo choo, grr, uh oh } \\
\text { Deletions: moo, yum yum }\end{array}$ & 10 \\
\hline Animals & Additions: dinosaur & 45 & $\begin{array}{l}\text { Additions: panda } \\
\text { Substitutions: bee, donkey, hen, }{ }^{*} \text { kitty, moose, pony, puppy, } \\
\text { rooster, sheep, teddy bear, turkey }\end{array}$ & 45 \\
\hline Vehicles & No changes & 14 & $\begin{array}{l}\text { Additions: crane } \\
\text { Substitutions: helicopter, sled, stroller, tricycle }\end{array}$ & 15 \\
\hline Toys & Additions: kite & 19 & $\begin{array}{l}\text { Additions: kite } \\
\text { Deletions: chalk } \\
\text { Substitutions: bat, bubbles, glue, play dough, puzzle }\end{array}$ & 18 \\
\hline Food and drink & Additions: mushrooms & 69 & $\begin{array}{l}\text { Additions: mushrooms } \\
\text { Substitutions: cereal, cheerios, cheese, coffee, cracker, donut, } \\
\text { french fries, gum, hamburger, jello, lollipop, muffin, } \\
\text { peanut butter, pickle, pizza, popcorn, popsicle, potato } \\
\text { chip, pretzel, pudding, pumpkin, raisin, sandwich, } \\
\text { sauce, spaghetti, toast, tuna, vanilla, vitamins }\end{array}$ & 69 \\
\hline
\end{tabular}




\section{APPENDIX B (Continued)}

\begin{tabular}{|c|c|c|c|c|}
\hline Category & English Modifications & $\begin{array}{l}n \text { of } \\
\text { Words }\end{array}$ & Mandarin Modifications & $\begin{array}{c}n \text { of } \\
\text { Words }\end{array}$ \\
\hline Clothing & No changes & 28 & $\begin{array}{l}\text { Substitutions: beads, belt, boots, diaper, jeans, mittens, } \\
\text { shorts, snowsuit, tights }\end{array}$ & 28 \\
\hline Body parts & No changes & 27 & Substitutions: owie, penis, toe, vagina & 27 \\
\hline $\begin{array}{l}\text { Small house- } \\
\text { hold items }\end{array}$ & $\begin{array}{l}\text { Additions: battery, pot, saw, } \\
\text { teapot, violin }\end{array}$ & 55 & $\begin{array}{l}\text { Additions: basin, battery, pot, teapot, violin } \\
\text { Substitutions: fork, jar, penny, plant, plate, tape, tray, vac- } \\
\text { uum, walker }\end{array}$ & 55 \\
\hline $\begin{array}{l}\text { Furniture and } \\
\text { rooms }\end{array}$ & No changes & 33 & $\begin{array}{l}\text { Deletions: basement, bedroom, crib } \\
\text { Substitutions: dryer, garage, high chair, oven, play pen, rock- } \\
\text { ing chair, shower, sink, sofa }\end{array}$ & 30 \\
\hline Outside things & Additions: umbrella, wheelbarrow & 33 & $\begin{array}{l}\text { Additions: umbrella, wheelbarrow } \\
\text { Substitutions: backyard, lawn mower, rock, sidewalk, swing }\end{array}$ & 33 \\
\hline Places to go & No changes & 22 & $\begin{array}{l}\text { Substitutions: camping, church, circus, downtown, gas } \\
\text { station, party, picnic, yard }\end{array}$ & 22 \\
\hline People & No changes & 29 & $\begin{array}{l}\text { Additions: maternal uncle, younger sister, younger brother, } \\
\text { maternal grandmother } \\
\text { Substitutions: baby, babysitter, babysitter's name, clown, } \\
\text { cowboy, fireman, lady, pet's name }\end{array}$ & 33 \\
\hline $\begin{array}{r}\text { Games and } \\
\text { routines }\end{array}$ & No changes & 25 & $\begin{array}{l}\text { Substitutions: breakfast, give me five!, no, shh, so big!, this } \\
\text { little piggy, turn around }\end{array}$ & 25 \\
\hline Action words & $\begin{array}{l}\text { Additions: ask, beep, bend, blink, } \\
\text { bounce, chatter, chew, come, } \\
\text { count, crash, crawl, cross, dial, } \\
\text { do, dream, fill, flip, fly, forget, } \\
\text { grab, grow, hang, happen, hop, } \\
\text { is, know, laugh, lay /lie, learn, } \\
\text { leave, let go, lift, light up, } \\
\text { move, pee, peek, poke, press, } \\
\text { remember, roar, roll, scatter, } \\
\text { scream, shout, shove, shut, } \\
\text { spin, spread, squat, squeak, } \\
\text { squeeze, step, stick, stuff, } \\
\text { swallow, tell, trade, trip, try, } \\
\text { turn, use, want, wear, } \\
\text { wiggle, wind (up), yell }\end{array}$ & 169 & $\begin{array}{l}\text { Additions: arrive, ask, bend, blink, brush (against), carry } \\
\text { (level), carry (on shoulder), chew, come, count, crash, } \\
\text { crawl, cross, descend, dial, do, dream, enter, fill, flip, fly, } \\
\text { follow, forget, get up, grab, grow, hang, happen, hide } \\
\text { (one's person), hop, insert, is, is able, know, laugh, lay/ } \\
\text { lie, learn, leave, let go, lift, light up, lose, move, pee, } \\
\text { peek, peel, pet, pick, pick up, pinch, place, poke, press, } \\
\text { remember, return, roar, roll, rub, scatter, shout, smell, } \\
\text { spin, spit, spread, squat, squeak, squeeze, steal, step, } \\
\text { stick, stir, stuff, swallow, tell, tie up, trade, trip, try } \\
\text { (hard), try (on), turn, use, want, wear (clothes), wear } \\
\text { (hat), wiggle, wind (up), yell } \\
\text { Substitutions: climb, fall, finish, fit, get, happen, hurry, share, } \\
\text { show, skate, smile, splash, tickle, watch }\end{array}$ & 190 \\
\hline $\begin{array}{l}\text { Descriptive } \\
\text { words }\end{array}$ & No changes & 63 & $\begin{array}{l}\text { Additions: well-behaved } \\
\text { Substitutions: asleep, awake, gentle, nice, orange, quiet }\end{array}$ & 64 \\
\hline Time words & No changes & 12 & Substitutions: later, tonight & 12 \\
\hline Pronouns & No changes & 25 & $\begin{array}{l}\text { Deletions: hers, his } \\
\text { Substitutions: her, him, it, me, my, she, them, us, yourself }\end{array}$ & 23 \\
\hline Question words & No changes & 7 & Additions: what time, what doing, $m a ?,{ }^{* *}$ how many, $n e^{* *}$ & 12 \\
\hline $\begin{array}{l}\text { Prepositions } \\
\text { and locations }\end{array}$ & No changes & 26 & $\begin{array}{l}\text { Deletions: about, around, away, back, for } \\
\text { Substitutions: next to, of, off, on top of, over }\end{array}$ & 21 \\
\hline $\begin{array}{l}\text { Quantifiers and } \\
\text { articles }\end{array}$ & No changes & 17 & (All substituted for Chinese classifiers) & 17 \\
\hline Helping verbs & No changes & 21 & (Substituted or deleted all but "can," "need to," and "want to") & 13 \\
\hline
\end{tabular}

* Note that many animal names that distinguish amongst sex (e.g., hen/rooster) and stage of development (e.g., cat/kitty) in English are simply modified with an adjective in Mandarin (e.g., mu3ji1, "mother chicken" versus gong1ji1, "male chicken"; xiao3 mao1, "little cat"). Thus, we chose to substitute the names of different animals instead of repeating the same characters on the checklist.

** Chinese question particle with no English equivalents. 